\title{
Electronic Customer Relationship Management in action: an example in business
}

\author{
Claudia Caridad Tusell-Rey ${ }^{1}$, Ricardo Tejeida-Padilla ${ }^{2}$, Carmen Fausta Rey-Benguría ${ }^{3}$ \\ ${ }^{1}$ Escuela Superior de Turismo, Instituto Politécnico Nacional, México, ceron01.ipn @ gmail.com \\ ${ }^{2}$ Escuela Superior de Turismo, Instituto Politécnico Nacional, México, ricardotp75@ hotmail.com \\ ${ }^{3}$ Universidad de Ciego de Ávila, Cuba, carmenrb2008@gmail.com
}

\begin{abstract}
Nowadays, Electronic Customer Relationship Management (eCRM) constitutes a key aspect for management in the tourism and business industry. The automatic analysis of the available information is a major part of eCRM. In this paper, we address the use of eCRM in the development of tourism and business, and we consider a case of study to determine the usefulness of computational intelligence algorithms. We find that computational intelligence algorithms are very accurate for the determination of Online Shoppers Purchasing Intention, and can be easily applied for marketing purposes.
\end{abstract}

Key words : customer relationship management, internet, online retail.

\section{INTRODUCTION}

The modern administration considers that the paradigm of management of relations with the clients (Customer Relationship Management, CRM) is fundamental for the survival of the organizations [1-3]. CRM is defined as all marketing activities aimed at establishing, developing and maintaining satisfactory relational exchanges with customers [4].

With the emergence of new information and communication technologies, CRM has evolved in the digital age, giving way to eCRM (electronic CRM), where marketing activities have at least one virtual component. In CRM and eCRM, three phases of a customer's life cycle are considered: start, maintenance, and retention or termination [5]. For the successful achievement of this process, three types of information are considered: customer information (Of-the-customer), customer information (For-the-customer) and customer information (By-the- customer) [6]. In all cases, valuable information is required.

Computational intelligence algorithms have been widely used for data preprocessing [7-15], classification [16-28], clustering [29-31], matching [32-34] and prediction [35-37], for several disciplines such as education [38-49], medicine [30, 50-52], engineering [21, 25, 34, 53-57], finances [27, 58, 59] and others [60-65].

In this article is presented an experimental work using different computational intelligence algorithms to determine the Online Shoppers Purchasing Intention, as an example of eCRM. We use a recently created dataset with the purpose to know which of the algorithms analyzed has the best performance under the circumstances described above.

The rest of the paper is organized as follows. Section 2 details some previous works and section 3 offers a discussion about the results obtained. Finally, the paper ends with some conclusions and future research suggestions.

\section{PREVIOUS WORKS}

Several dimensions or attributes of eCRM have been identified [1, 66, 67], among them the quality of the information, the integrated marketing channels, the level of personalization and the use of attributes of social networks.

Due to the large amount of content that is posted daily in the form of reviews, manual analysis of reviews becomes difficult and time consuming. For this reason, various computational strategies have been used to divide the reviews into three types: positive, neutral or negative, through the analysis of feelings [68-70].

This theme is very active at present, having been applied in countries such as China [71], the Sultanate of Oman [68], Serbia [72], Spain [73, 74], among others. Text mining has also been used to establish tourist preferences in Japan [75].

In the scientific literature of the state of the art, it is possible to find research works that report using eCRM strategies. The combination of tourism and the Internet (Internet + Travel) allows people to obtain more detailed travel information. Yu and collaborators automatically extracted reviews of Chinese 
tourist attractions from a Japanese travel website called 4Travel [76]. In Law and colleagues' research, user searches are used to forecast tourism demand in Macao [77]. Also, Sun and collaborators investigated the forecast of tourist demand, this time in Beijing [78]. In this case, the kernel extreme learning machine (KELM) was used. In this case, no data is available.

Zhang and collaborators have also investigated the forecast of the demand for sports tourism [79], while other researchers have done so in the classification of tourist scenarios [80, 81]. However, the above studies incorporate few datasets, and to complicate matters, many of the datasets used are not public, nor are they available for use. However, last year, an Online Shoppers Purchasing Intention dataset was made publicly available [82].

The No Free Lunch theorems [83] argue that there is no superiority of one classifier over others, over all datasets and all performance measures. However, it is possible to analyze the performance of classifiers in some particular scenarios, such as Online Shoppers Purchasing Intention.

\section{RESULTS AND DISCUSSION}

\subsection{Datasets}

In this section, we describe the dataset that will be used to evaluate performance of the computational intelligence classifiers. We selected the Online Shoppers Purchasing Intention dataset [82]. This dataset was donated to the Machine Learning Repository of the University of California at Irvine [84], in 2018.

The dataset consists of 12330 user sessions. According to the donors, the dataset "was formed so that each session would belong to a different user in a 1-year period to avoid any tendency to a specific campaign, special day, user profile, or period". The dataset has 10 numerical and 8 categorical attributes (Table 1). The "Revenue" is the class label.

As shown, the dataset has 17 conditional features. The dataset is imbalanced, due to there are 10422 clients with no purchasing intentions, and only 1908 clients with purchasing intentions, for an imbalance ratio $\mathrm{IR}=5.46$.

\subsection{Algorithms to compare}

In this section, the computational intelligence algorithms that will be evaluated in the present investigation are addressed. We used six simple classifiers: Nearest Neighbor [85], Naïve Bayes [86], C4.5 [87], Multilayer Perceptron [88], Support Vector Machines [89] and RIPPER [90]. In addition, we used three classifier ensembles: AdaBoost.M1 [91], Bagging [92] and Random Forest [93].
Nearest Neighbor was proposed by Cover and Hart [85], and uses distances to determine the class of the unknown pattern. To do so, it compares the patter against every training sample, and assigns the class of the closest sample. Naive Bayes is a classifier based on the Bayes theorem of probabilities [86]. It computes the conditional probability of the unknown patter to belong to each of the training classes, and assigns it the most probable class.

Table 1: Attributes of the used dataset

\begin{tabular}{|c|c|}
\hline Name & Description \\
\hline \multicolumn{2}{|r|}{ Continuous attributes } \\
\hline Administrative & $\begin{array}{l}\text { Number of pages visited by the visitor } \\
\text { about account management }\end{array}$ \\
\hline $\begin{array}{l}\text { Administrative } \\
\text { duration }\end{array}$ & $\begin{array}{l}\text { Total amount of time (in seconds) spent } \\
\text { by the visitor on account management } \\
\text { related pages }\end{array}$ \\
\hline Informational & $\begin{array}{l}\text { Number of pages visited by the visitor } \\
\text { about web site, communication and } \\
\text { address information of the shopping site }\end{array}$ \\
\hline $\begin{array}{l}\text { Informational } \\
\text { duration }\end{array}$ & $\begin{array}{l}\text { Total amount of time (in seconds) spent } \\
\text { by the visitor about product related } \\
\text { pages }\end{array}$ \\
\hline Product related & $\begin{array}{l}\text { Number of pages visited by the visitor } \\
\text { about product related pages }\end{array}$ \\
\hline $\begin{array}{l}\text { Product related } \\
\text { duration }\end{array}$ & $\begin{array}{l}\text { Total amount of time (in seconds) spent } \\
\text { by the visitor in product related pages }\end{array}$ \\
\hline Bounce rate & $\begin{array}{l}\text { Average bounce rate value of pages } \\
\text { visited }\end{array}$ \\
\hline Exit rate & $\begin{array}{l}\text { Average exit rate value of the pages } \\
\text { visited }\end{array}$ \\
\hline Page Value & $\begin{array}{l}\text { Average page value of the pages visited } \\
\text { by the visitor }\end{array}$ \\
\hline Special day & $\begin{array}{l}\text { Closeness of the site visiting time to a } \\
\text { special day }\end{array}$ \\
\hline \multicolumn{2}{|r|}{ Nominal Attributes } \\
\hline $\begin{array}{l}\text { Operating } \\
\text { system }\end{array}$ & Operating system of the visitor \\
\hline Browser & Browser of the visitor \\
\hline Region & $\begin{array}{l}\text { Geographic region from which the } \\
\text { session has been started by the visitor }\end{array}$ \\
\hline Traffic type & $\begin{array}{l}\text { Traffic source by which the visitor has } \\
\text { arrived at the Web site (e.g., banner, } \\
\text { SMS, direct) }\end{array}$ \\
\hline Visitor Type & $\begin{array}{l}\text { Visitor type as "New Visitor, Returning } \\
\text { Visitor and Other" }\end{array}$ \\
\hline Weekend & $\begin{array}{l}\text { Boolean value indicating whether the } \\
\text { date of the visit is weekend }\end{array}$ \\
\hline Month & Month value of the visit date \\
\hline Revenue & $\begin{array}{l}\text { Class label indicating whether the visit } \\
\text { has been finalized with a transaction }\end{array}$ \\
\hline $\begin{array}{l}\text { Operating } \\
\text { system }\end{array}$ & Operating system of the visitor \\
\hline
\end{tabular}


C4.5 is a Decision Tree classifier, proposed by Quinlan [87]. It uses the concept of entropy and information gain to split the training set, and to form a tree structure. Then, the unknown pattern "travels" the tree according to its feature values, until it reaches a leaf. Then, the pattern is assigned to the class.

Multilayer Perceptron (MLP) is a network of simple "neurons" or "Perceptrons" [88]. It has its neurons grouped in layers of distinct levels. Each of the layers is formed by a set of neurons and three different types of layers are distinguished: the input layer, the hidden layers and the output layer. The unknown pattern is presented to the input layer of the network, and the output layer gives the corresponding class.

Support Vector Machines (SVM) are classifier based on kernels [89]. They try to find a hyperspace of characteristic with linear separability of the classes. We used the Sequential Minimal Optimization (SMO) procedure for solving the quadratic programming problem that arises during the training of SVM. SMO was implemented by John Platt [94].

RIPPER (Repeated Incremental Pruning to Produce Error Reduction) is a classifier which finds decision rules, based on the training instances values [90]. Then, after the rules are founded, the pattern is presented to the rules, and a decision according to its class is made.

AdaBoost.M1 is a classifier ensemble of decision trees [91]. It uses several $\mathrm{C} 4.5$ classifiers as base classifiers, each of them sequentially training to reduce the overall error of the ensemble. Once the ensemble is trained, the unknown pattern is presented, and the class with a majority of votes among the base classifiers is assigned.

Bagging is another classifier ensemble [92], which also uses C4.5 trees as base classifiers. However, it trains each of the base classifiers with a portion of the training set, named a bag. As AdaBoost.M1, the class with a majority of votes among the base classifiers is assigned to the unknown pattern.

Different from previous classifier ensembles, Random Forest [93] construct a forest of decision trees. But those trees are built by random selection of features. Class assignment is made by majority vote.

For the application of the above mentioned classifiers, we used the WEKA (Waikato Environment for Knowledge Analysis) software [95], in its version 3.8.3.

\subsection{Performance measures}

Due to data imbalance, we used the measures F1-score [96], Matthews Correlation Coefficient (MCC) [97] and the Area under the ROC Curve (AUC) [96]. Those measures are based on a confusion matrix (Figure 1). The equations for the computation of such measures directly from the confusion matrix are given below.

\begin{tabular}{|l|l|c|c|}
\cline { 3 - 4 } \multicolumn{2}{c|}{} & \multicolumn{2}{c|}{ True Condition } \\
\cline { 3 - 4 } \multicolumn{2}{c|}{} & Positive & Negative \\
\hline \multirow{3}{*}{$\begin{array}{c}\text { Predicted } \\
\text { Condition }\end{array}$} & Positive & $t p$ & $f p$ \\
\cline { 2 - 4 } & Negative & $f n$ & $t n$ \\
\hline
\end{tabular}

Figure 1: Confusion matrix

$$
\begin{aligned}
& F 1=\frac{2 *\left(\frac{t p}{t p+f p}\right) *\left(\frac{t p}{t p+f n}\right)}{\left(\frac{t p}{t p+f p}\right)+\left(\frac{t p}{t p+f n}\right)} \\
& A U C=\frac{1}{2}\left(\left(\frac{t p}{i p+\int p}\right)+\left(\frac{t p}{\iota p+f n}\right)\right) \\
& M C C=\frac{t p * t n-f p * f n}{\sqrt{(t p+f p)(t p+f n)(t n+f p)(t n+f n)}}
\end{aligned}
$$

Each algorithm was tested with a 5-fold cross validation procedure as model validation technique.

\subsection{Discussion}

Each algorithm was tested in the WEKA software [95] using the default parameters offered. Table 2 shows the results for the compared performance measures. Best results for each measure are highlighted in bold.

As you can see in Table 2 and Figure 2, as expected, for the F1 measure the best results correspond to Bagging and Random Forest. However, for the Mathews Correlation coefficient, the algorithms with best results was RIPPER. For the Area under the ROC curve, Bagging obtained the best results, closely followed by Random Forest.

The experiments show that classifier ensembles obtained very good results in the prediction of Online Shoppers Purchasing Intention. In particular, the Bagging classifier was the best for two of the three analyzed performance measures, having an $\mathrm{f1}$ score of 0.942, and an AUC of 0.927.

Table 2: Results of the compared algorithms

\begin{tabular}{|l|l|l|l|}
\hline Algorithms & F1 & MCC & AUC \\
\hline Naïve Bayes & 0.886 & 0.434 & 0.838 \\
\hline MLP & 0.934 & 0.555 & 0.887 \\
\hline SVM & 0.934 & 0.468 & 0.666 \\
\hline NN & 0.891 & 0.254 & 0.625 \\
\hline AdaBoost.M1 & 0.935 & 0.579 & 0.914 \\
\hline Bagging & $\mathbf{0 . 9 4 2}$ & 0.598 & $\mathbf{0 . 9 2 7}$ \\
\hline RIPPER & 0.940 & $\mathbf{0 . 6 1 0}$ & 0.807 \\
\hline C4.5 & 0.938 & 0.568 & 0.786 \\
\hline Random Forest & $\mathbf{0 . 9 4 2}$ & 0.592 & 0.926 \\
\hline
\end{tabular}




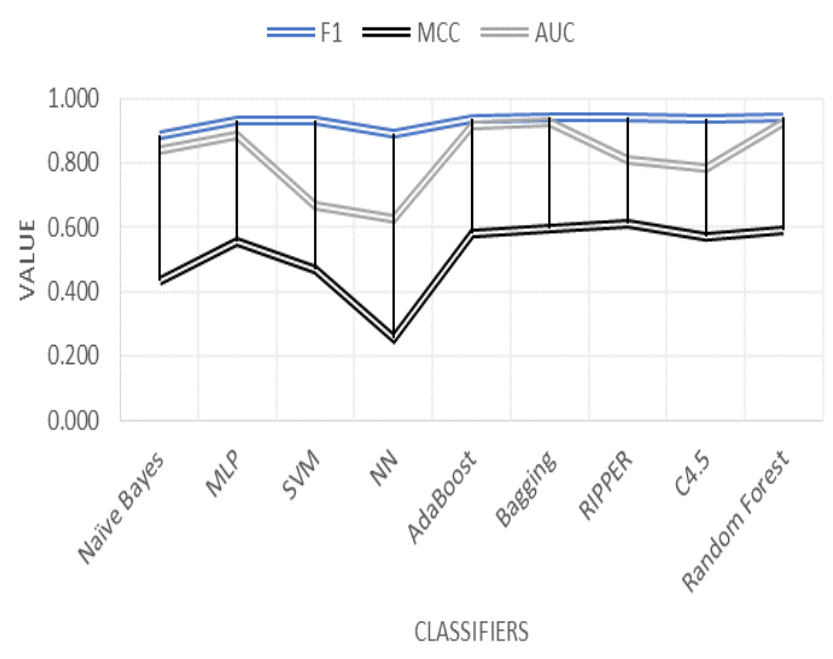

Figure 2. Results of the compared algorithms

\section{CONCLUSION}

In the tourism and business environment, Customer Relationship Management has an increase role. In the XXI century, with the availability of internet technologies, the Electronic Customer Relationship Management (eCRM) is a must be for almost all enterprises. Within it, the analysis of information, with computational intelligence algorithms is the key for marketing and development of user-centered strategies.

We prove in this paper the usefulness of computational intelligence algorithms in eCRM, for the automatic classification of Online Shoppers Purchasing Intention. With respect to other and diverse applications, there is an ocean of possibilities [98-117]. As future work, we want to apply computational intelligence algorithm to other tourism and business activities.

\section{ACKNOWLEDGEMENT}

The authors would like to thank the Instituto Politécnico Nacional (Secretaría Académica, Comisión de Operación y Fomento de Actividades Académicas, Secretaría de Investigación y Posgrado, Centro de Innovación y Desarrollo Tecnológico en Cómputo and Escuela Superior de Turismo), the Consejo Nacional de Ciencia y Tecnología, and Sistema Nacional de Investigadores for their economical support to develop this work.

\section{REFERENCES}

1. P. Mekkamol, S. Piewdang, and S. Untachai, Modeling e-CRM for community tourism in Upper Northeastern Thailand. Procedia-Social and Behavioral Sciences, Vol. 88: pp. 108-117, 2013.
2. J. Dubihlela, and P. Molise-Khosa, Impact of e-CRM implementation on customer loyalty customer retention and customer profitability for hoteliers along the Vaal Meander of South Africa. Mediterranean Journal of Social Sciences, 2014.

3. G. Mastorakis, et al., E-CRM in tourism exploiting emerging information and communication technologies. Anatolia, Vol. 26(1): pp. 32-44, 2015.

4. R.M. Morgan, and S.D. Hunt, The commitment-trust theory of relationship marketing. Journal of marketing, Vol. 58(3): pp. 20-38, 1994.

5. F.R. Dwyer, P.H. Schurr, and S. Oh, Developing buyer-seller relationships. Journal of marketing, Vol. 51(2): pp. 11-27, 1987.

6. C.-H. Park, and Y.-G. Kim. A framework of dynamic CRM: linking marketing with information strategy. Business Process Management Journal, Vol. 9(5): pp. 652-671, 2003.

7. M. A. Medina-Pérez, M. García-Borroto, Y. Villuendas-Rey, and J. Ruiz-Shulcloper. Selecting objects for ALVOT, in Iberoamerican Congress on Pattern Recognition, pp. 606-613, 2006.

8. Y. Villuendas-Rey, C. Yáñez-Márquez, and J. L. Velázquez-Rodríguez. Generic extended multigranular sets for mixed and incomplete information systems, Soft Computing, Vol 24, pp. 6119-6137, 2020.

9. O. Camacho-Nieto, C. Yáñez-Márquez, and Y. Villuendas-Rey. Undersampling Instance Selection for Hybrid and Incomplete Imbalanced Data, Journal of Universal Computer Science (J.UCS), Vol. 26, pp. 698-719, 2020.

10. A. Rangel-Díaz de la Vega, Y. Villuendas-Rey, C. Yáñez-Márquez, and O. Camacho-Nieto. The Naïve Associative Classifier with Epsilon disambiguation, IEEE Access, Vol 8, pp. 51862-51870, 2020.

11. M. García-Borroto, et al. Finding small consistent subset for the nearest neighbor classifier based on support graphs. in Iberoamerican Congress on Pattern Recognition. Springer, 2009.

12. Y. Villuendas-Rey, Y. Caballero-Mota, and M.M. García-Lorenzo. Intelligent feature and instance selection to improve nearest neighbor classifiers. in Mexican International Conference on Artificial Intelligence. 2012. Springer.

13. Y. Villuendas-Rey, Y. Caballero-Mota, and M.M. García-Lorenzo. Prototype selection with compact sets and extended rough sets. in Ibero-American Conference on Artificial Intelligence. 2012. Springer.

14. Y. Villuendas-Rey, Y. and M.M. Garcia-Lorenzo, Attribute and case selection for $\mathrm{nn}$ classifier through rough sets and naturally inspired algorithms. Computación y Sistemas, Vol. 18(2): pp. 295-311, 2014.

15. A. V. Uriarte-Arcia, I. López-Yáñez, and C. Yáñez-Márquez. One-hot vector hybrid associative classifier for medical data classification, PloS one, Vol. 9, e95715, 2014. 
16. M. E. Acevedo-Mosqueda, C. Yáñez-Márquez, and I. López-Yáñez. Alpha-Beta bidirectional associative memories: theory and applications, Neural Processing Letters, Vol. 26, pp. 1-40,(2007.

17. A. García-Floriano, A. Ferreira-Santiago, O. Camacho-Nieto, and C. Yáñez-Márquez. A machine learning approach to medical image classification: Detecting age-related macular degeneration in fundus images, Computers \& Electrical Engineering, Vol. 75, pp. 218-229, 2019.

18. R. Ramírez-Rubio, M. Aldape-Pérez, C. Yáñez-Márquez, I. López-Yáñez, and O. Camacho-Nieto. Pattern classification using smallest normalized difference associative memory, Pattern Recognition Letters, vol. 93, pp. 104-112, 2017.

19. M. E. Acevedo, C. Yáñez-Márquez, and M. A. Acevedo. Associative models for storing and retrieving concept lattices, Mathematical Problems in Engineering, Vol. 2010, 356029, pp. 1-27, 2010.

20. E. Guzmán, O. Pogrebnyak, C. Yañez, and L. P. S. Fernandez. Morphological transform for image compression, EURASIP Journal on advances in signal processing, vol. 2008, p. 426580, 2008.

21. I. Salgado-Ramos. C. Yáñez-Márquez, O. Camacho-Nieto, and I. Chairez-Oria. Adaptive control of discrete-time nonlinear systems by recurrent neural networks in quasi-sliding mode like regime, International Journal of Adaptive Control and Signal Processing, Vol. 31, pp. 83-96, 2017.

22. S. Dong, Q. Fang, B. J. Falaye, G. H. Sun, C. Yáñez-Márquez, and S. H. Dong. Exact solutions to solitonic profile mass Schrödinger problem with a modified Pöschl-Teller potential, Modern Physics Letters A, Vol. 31, 1650017, 2016.

23. A. V. Uriarte-Arcia, I. López-Yáñez, C. Yáñez-Márquez, J. Gama, and O. Camacho-Nieto. Data stream classification based on the gamma classifier, Mathematical Problems in Engineering, Vol. 2015, Article 939175, pp. 1-17, 2015.

24. R. L. Ulloa-Cazarez, C. López-Martín, A. Abran, and C. Yáñez-Márquez. Prediction of online students performance by means of genetic programming, Applied Artificial Intelligence, Vol. 32, pp. 858-881, 2018.

25. M. M. De Luis, A. J. Argüelles Cruz, A. V. Uriarte Arcia, and C. Yáñez-Márquez. Green information technology influence on car owners' behavior: Considerations for their operative support in collaborative eLearning and social networks, Computers in Human Behavior, Vol. 51, pp. 792-802, 2015.

26. A. García-Floriano, C. Yáñez-Márquez, and O. Camacho-Nieto. Detection of Age-Related Macular Degeneration in Fundus Images by an Associative Classifier, IEEE Latin America Transactions, Vol. 16, pp. 933-939, 2018.

27. R. C. López, G. H. Sun, O. Camacho-Nieto, C. Yáñez-Márquez, C., and S. H. Dong. Analytical traveling-wave solutions to a generalized Gross-Pitaevskii equation with some new time and space varying nonlinearity coefficients and external fields, Physics Letters A, Vol. 381, pp. 2978-2985, 2017.

28. I. Salgado, I. Chairez, O. Camacho, and C. Yañez. Super-twisting sliding mode differentiation for improving PD controllers performance of second order systems, ISA transactions, vol. 53, pp. 1096-1106, 2014.

29. A. Ferreira-Santiago, C. López-Martín, and C. Yáñez-Márquez. Metaheuristic optimization of multivariate adaptive regression splines for predicting the schedule of software projects, Neural Computing \& Applications, Vol. 27, pp. 2229-2240, 2016.

30. Y. Villuendas, C. Yanez, and C. Rey. Attributes and cases selection for social data classification, IEEE Latin America Transactions, Vol. 13, pp. 3370-3381, 2015.

31. I. López-Yáñez, A. J. Argüelles-Cruz, O. Camacho-Nieto, and C. Yáñez-Márquez. Pollutants time-series prediction using the Gamma classifier, International Journal of Computational Intelligence Systems, vol. 4, pp. 680-711, 2011.

32. A. Ramirez, I. Lopez, Y. Villuendas, and C. Yanez. Evolutive improvement of parameters in an associative classifier, IEEE Latin America Transactions, Vol. 13, pp. 1550-1555, 2015.

33. J. L. Velázquez-Rodríguez, Y. Villuendas-Rey, O. Camacho-Nieto, and C. Yáñez-Márquez. A Novel and Simple Mathematical Transform Improves the Perfomance of Lernmatrix in Pattern Classification, Mathematics, Vol. 8, 732, pp. 1-46, 2020.

34. I. López-Yáñez, L. Sheremetov, and C. Yáñez-Márquez. A novel associative model for time series data mining, Pattern Recognition Letters, vol. 41, pp. 23-33, 2014.

35. M. D. Lytras, H. Mathkour, H. I. Abdalla, C. Yáñez-Márquez, and P. O. De Pablos. The Social Media in Academia and EducationResearch R-evolutions and a Paradox: Advanced Next Generation Social Learning Innovation, J. UCS, vol. 20, pp. 1987-1994, 2014.

36. Y. Villuendas-Rey, C. F. Rey-Benguría, O. Camacho-Nieto, and C. Yáñez-Márquez. Prediction of High Capabilities in the Development of Kindergarten Children, Applied Sciences, Vol. 10, 2710, pp. 1-29, 2020.

37. C. Yáñez-Márquez, M. Aldape-Perez, I. López-Yáñez, and O. Camacho-Nieto. Emerging computational tools: Impact on engineering education and computer science learning, International Journal of Engineering Education, pp. 533-542, 2014.

38. M. Aldape-Pérez, C. Yáñez-Márquez, O. Camacho-Nieto, I. López-Yáñez, and A.-J. Argüelles-Cruz. Collaborative learning based on associative models: Application to pattern 
classification in medical datasets, Computers in Human Behavior, vol. 51, pp. 771-779, 2015.

39. M. Aldape-Pérez, A. Alarcón-Paredes, C. Yáñez-Márquez, I. López-Yáñez, and O. Camacho-Nieto. An Associative Memory Approach to Healthcare Monitoring and Decision Making, Sensors, Vol. 18(8), 2690, pp. 1-11, 2018.

40. A. Ferreira-Santiago, C. Yanez-Marquez, I. Lopez-Yanez, O. Camacho-Nieto, M. Aldape-Perez, and A. J. Arguelles-Cruz. Enhancing engineering education through link prediction in social networks, International Journal of Engineering Education, pp. 1566-1578, 2016.

41. S. Cerón-Figueroa, I. López-Yáñez, Y. Villuendas-Rey, O. Camacho-Nieto, M. Aldape-Pérez, and C. Yáñez-Márquez. Instance-based ontology matching for open and distance learning materials, International Review of Research in Open and Distributed Learning, Vo. 18, pp. 177-195, 2017.

42. A. García-Floriano, A. Ferreira-Santiago, C. Yáñez-Márquez, O. Camacho-Nieto, M. Aldape-Pérez, and Y. Villuendas-Rey. Social Web Content Enhancement in a Distance Learning Environment: Intelligent Metadata Generation for Resources, International Review of Research in Open and Distributed Learning, vol. 18, pp. 161-176, 2017.

43. S. Ortiz-Ángeles, Y. Villuendas-Rey, I. López-Yáñez, O. C. Nieto, and C. Yáñez-Márquez. Electoral Preferences Prediction of the YouGov Social Network Users Based on Computational Intelligence Algorithms, $J$. UCS, vol. 23, pp. 304-326, 2017.

44. R. Ramírez-Rubio, M. Aldape-Pérez, C. Yáñez-Márquez, I. López-Yáñez, and O. Camacho-Nieto. Pattern classification using smallest normalized difference associative memory, Pattern Recognition Letters, vol. 93, pp. 104-112, 2017.

45. Y. Villuendas-Rey, C. F. Rey-Benguría, Á. Ferreira-Santiago, O. Camacho-Nieto, and C. Yáñez-Márquez. The naïve associative classifier (NAC): a novel, simple, transparent, and accurate classification model evaluated on financial data, Neurocomputing, vol. 265, pp. 105-115, 2017.

46. J. A. Antón-Vargas, Y. Villuendas-Rey, C. Yáñez-Márquez, I. López-Yáñez, and O. Camacho-Nieto. Improving the performance of an associative classifier by Gamma rough sets based instance selection, International Journal of Pattern Recognition and Artificial Intelligence, vol. 32, p. 1860009, 2018.

47. E. Barroso, Y. Villuendas, and C. Yanez. Bio-inspired algorithms for improving mixed and incomplete data clustering, IEEE Latin America Transactions, vol. 16, pp. 2248-2253, 2018.

48. A. Alarcón-Paredes, Z. Rebolledo-Nandi, I. P. Guzmán-Guzmán, C. Yáñez-Márquez, and G. A. Alonso. A non-invasive glucose level estimation in a multi-sensing health care monitoring system, Technology and Health care, Vol. 26, pp. 203-208, 2018.

49. Y. O. Serrano-Silva, Y. Villuendas-Rey, and C. Yáñez-Márquez. Automatic feature weighting for improving financial Decision Support Systems, Decision Support Systems, vol. 107, pp. 78-87, 2018.

50. Y. Villuendas-Rey, M. D. Alanis-Tamez, C. Rey-Benguría, C. Yáñez-Márquez, and O. C. Nieto. Medical Diagnosis of Chronic Diseases Based on a Novel Computational Intelligence Algorithm, J. UCS, vol. 24, pp. 775-796, 2018.

51. C. Yáñez-Márquez, I. López-Yáñez, M. Aldape-Pérez, O. Camacho-Nieto, A. J. Argüelles-Cruz, and Y. Villuendas-Rey. Theoretical Foundations for the Alpha-Beta Associative Memories: 10 Years of Derived Extensions, Models, and Applications, Neural Processing Letters, vol. 48, pp. 811-847, 2018.

52. M. Aldape-Pérez, C. Yáñez-Márquez, O. Camacho-Nieto, and A. Ferreira-Santiago. Feature selection using associative memory paradigm and parallel computing, Computación y Sistemas, Vol. 17, pp. 41-52, 2013.

53. Y. Villuendas-Rey. Maximal similarity granular rough sets for mixed and incomplete information systems, Soft Computing, vol. 23, pp. 4617-4631, 2019.

54. Y. Villuendas-Rey, J. A. Hernández-Castaño, O. Camacho-Nieto, C. Yáñez-Márquez, and I. López-Yañez. NACOD: A Naïve Associative Classifier for Online Data, IEEE Access, vol. 7, pp. 117761-117767, 2019.

55. Y. Villuendas-Rey, C. Yáñez-Márquez, J. A. Antón-Vargas, and I. López-Yáñez. An Extension of the Gamma Associative Classifier for Dealing With Hybrid Data, IEEE Access, vol. 7, pp. 64198-64205, 2019.

56. J. E. Luján-García, M. A. Moreno-Ibarra, Y. Villuendas-Rey, and C. Yáñez-Márquez. Fast COVID-19 and Pneumonia Classification Using Chest X-ray Images, Mathematics, Vol. 8, 1423, pp. 1-19 2020.

57. C. Yanez-Marquez, I. Lopez-Yanez, O. Camacho-Nieto, and A. J. Arguelles-Cruz. BDD-based algorithm for the minimum spanning tree in wireless ad-hoc network routing, IEEE Latin America Transactions, vol. 11, pp. 600-601, 2013

58. J. A. Hernández-Castaño, Y. Villuendas-Rey, O. Camacho-Nieto, and C. Yáñez-Márquez. Experimental platform for intelligent computing (EPIC), Computación y Sistemas, vol. 22, pp. 245-253, 2018.

59. J. L. Velázquez-Rodríguez, Y. Villuendas-Rey, C. Yáñez-Márquez, I. López-Yáñez, and O. Camacho-Nieto. Granulation in Rough Set Theory: A novel perspective, International Journal of Approximate Reasoning, Vol. 124, pp. 27-39, 2020.

60. C. Yáñez-Márquez. Toward the bleaching of the black boxes: minimalist machine learning. IT Professional, Vol. 22, pp. 51-56, 2020. 
Claudia Caridad Tusell-Rey et al., International Journal of Emerging Trends in Engineering Research, 8(10), October 2020, 7214 - 7222

61. A. Rangel-Díaz de la Vega, Y. Villuendas-Rey, C. Yáñez-Márquez, O. Camacho-Nieto, and I. López-Yáñez. Impact of Imbalanced Datasets Preprocessing in the Performance of Associative Classifiers, Applied Sciences, Vol. 10, 2779, pp. 1-19, 2020.

62. G. H. Sun, C. Y. Chen, H. Taud, C. Yáñez-Márquez, and S. H. Dong. Exact solutions of the 1D Schrödinger equation with the Mathieu potential. Physics Letters A, 126480, 2020.

63. J. E. Luján-García, C. Yáñez-Márquez, Y. Villuendas-Rey, and O. Camacho-Nieto. A Transfer Learning Method for Pneumonia Classification and Visualization. Applied Sciences, Vo. 10, no. 8, 2908, 2020.

64. H. Calvo and A. Gelbukh. Unsupervised learning of ontology-linked selectional preferences, In Iberoamerican Congress on Pattern Recognition. Springer, Berlin, Heidelberg pp. 418-424, 2015.

65. A. Gelbukh and H. Calvo. Applications, Studies in Computational Intelligence, Springer, 765, pp. 69-83, 2018.

66. N. R. Ab Hamid, A.Y. Cheng, and R.M. Akhir, Dimensions of E-CRM: an empirical study on hotels' web sites. Journal of Southeast Asian Research, Vol. 2(11): pp. 1-15, 2011.

67. A. Papaioannou, et al., Exploring E-CRM application: The case of tourism and hospitality industry in greece. Journal of Regional Socio-Economic Issues (Jrsei), Vol. 4(1): pp. 75-84, 2014.

68. V. Ramanathan, and T. Meyyappan. Twitter Text Mining for Sentiment Analysis on People's Feedback about Oman Tourism. in 2019 4th MEC International Conference on Big Data and Smart City (ICBDSC). 2019. IEEE.

69. M. Afzaal, M. Usman, and A. Fong. Tourism Mobile App With Aspect-Based Sentiment Classification Framework for Tourist Reviews. IEEE Transactions on Consumer Electronics, Vol. 65(2): pp. 233-242, 2019.

70. A. R. Alaei, S. Becken, and B. Stantic. Sentiment analysis in tourism: capitalizing on big data. Journal of Travel Research, Vol. 58(2): pp. 175-191, 2019.

71. Y. Fu, et al. Predictive Accuracy of Sentiment Analytics for Tourism: A Metalearning Perspective on Chinese Travel News. Journal of Travel Research, Vol. 58(4): pp. 666-679, 2019.

72. O. Grljević, Z. Bošnjak, and S. Bošnjak, Contemporary data analysis techniques for online reputation management in hospitality and tourism. Facta Universitatis, Series: Economics and Organization, Vol. 16(1): pp. 59-73, 2019.

73. A. García, S. Gaines, and M.T. Linaza. A lexicon based sentiment analysis retrieval system for tourism domain. e-Review of Tourism Research, Vol. 10(2): pp. 35-38, 2012.

74. M. R. González-Rodríguez, R. Martínez-Torres, and S. Toral. Post-visit and pre-visit tourist destination image through eWOM sentiment analysis and perceived helpfulness. International Journal of Contemporary Hospitality Management, Vol. 28(11): pp. 2609-2627, 2016.

75. C. Zeng, et al. Text mining of tourism preference in a multilingual site. IEEJ Transactions on Electrical and Electronic Engineering, Vol. 14(4): pp. 590-596, 2019.

76. C. Yu, et al. Sentiment Analysis of Japanese Tourism Online Reviews. Journal of Data and Information Science, Vol. 4(1): p. 89-113, 2019.

77. R. Law, et al. Tourism demand forecasting: A deep learning approach. Annals of Tourism Research, Vol. 75: pp. 410-423, 2019.

78. S. Sun, et al. Forecasting tourist arrivals with machine learning and internet search index. Tourism Management, Vol. 70: pp. 1-10, 2019.

79. F. Zhang, Q. Jiang, and Z. Wang. Forecasting Mode of Sports Tourism Demand Based on Support Vector Machine. in Proceedings of the 5th International Conference on Frontiers of Educational Technologies. 2019. ACM.

80. T. Qi, Y. Xu, and H. Ling. Tourism scene classification based on multi-stage transfer learning model. Neural computing and applications, Vol. 31(8): pp. 4341-4352, 2019.

81. N. Saito, et al. Classification of tourism categories based on heterogeneous features considering existence of reliable results. in International Workshop on Advanced Image Technology (IWAIT) 2019. 2019. International Society for Optics and Photonics.

82. C. O. Sakar, et al. Real-time prediction of online shoppers' purchasing intention using multilayer perceptron and LSTM recurrent neural networks. Neural Computing and Applications, Vol. 31(10): pp. 6893-6908, 2019.

83. D. H. Wolpert, and W. G. Macready. No free lunch theorems for optimization. IEEE transactions on evolutionary computation, Vol. 1(1): pp. 67-82, 1997.

84. D. Dua, and C. Graff. UCI Machine Learning Repository [http://archive.ics.uci.edu/ml]. 2019.

85. T. Cover, and P. Hart. Nearest neighbor pattern classification. IEEE transactions on information theory, Vol. 13(1): pp. 21-27, 1967.

86. G. H. John, and P. Langley. Estimating continuous distributions in Bayesian classifiers. in Eleventh Conference on Uncertainty in Artificial Intelligence. 1995. San Mateo.

87. J. R. Quinlan, C4. 5: programs for machine learning. 1993: Morgan Kaufman.

88. D. W. Ruck, et al. Target recognition: Conventional and neural network approaches. in International 1989 Joint Conference on Neural Networks. 1989. IEEE.

89. V. Vapnik. The nature of statistical learning theory. 1995: Springer.

90. W. W. Cohen. Fast effective rule induction, in Machine learning proceedings 1995, Elsevier. pp. 115-123, 1995. 
91. Y. Freund, and R.E. Schapire. Experiments with a new boosting algorithm. in icml. 1996. Citeseer.

92. L. Breiman. Bagging predictors. Machine learning, Vol. 24(2): pp. 123-140, 1996.

93. L. Breiman. Random forests. Machine learning, Vol. 45(1): pp. 5-32, 2001.

94. J. Platt. Sequential minimal optimization: A fast algorithm for training support vector machines, in Advances in Kernel Methods - Support Vector Learning, B. MSchoelkopf, C. Burges, and A. Smola, Editors. 1998, Microsoft.

95. M. Hall, et al. The WEKA data mining software: an update. ACM SIGKDD explorations newsletter, Vol. 11(1): pp. 10-18, 2009.

96. M. Sokolova, N. Japkowicz, and S. Szpakowicz. Beyond accuracy, F-score and ROC: a family of discriminant measures for performance evaluation. in Australasian joint conference on artificial intelligence. 2006. Springer.

97. B. W. Matthews. Comparison of the predicted and observed secondary structure of T4 phage lysozyme. Biochimica et Biophysica Acta (BBA)-Protein Structure, Vol. 405(2): pp. 442-451, 1975.

98. H. Calvo. Opinion analysis in social networks using antonym concepts on graphs, In International Conference on Future Data and Security Engineering (pp. 109-120). Springer, Cham, 2015.

99. H. Calvo. Augmenting word space models for Word Sense Discrimination using an automatic thesaurus, In International Conference on Natural Language Processing (pp. 100-107). Springer, Berlin, Heidelberg, 2008.

100.M. A. Moreno-Armendáriz, H. Calvo, C.A. Duchanoy, A. P. López-Juárez, I.A. Vargas-Monroy and M.S. Suarez-Castañon. Deep Green Diagnostics: Urban Green Space Analysis Using Deep Learning and Drone Images. Sensors, Vol. 19(23), 5287, 2019.

101.H. Calvo, J.L. Paredes and J. Figueroa-Nazuno. Measuring concept semantic relatedness through common spatial pattern feature extraction on EEG signals. Cognitive Systems Research, Vol. 50, 36-51, (2018).

102.S. Ortiz-Ángeles, Y. Villuendas-Rey, C. Yáñez-Márquez, I. López-Yáñez, and O. Camacho-Nieto. Determining Electoral Preferences in Mexican Voters by Computational Intelligence Algorithms, IEEE Latin America Transactions, Vol. 18, pp. 704-713, 2020.

103.C. Lopez-Martin. Applying a general regression neural network for predicting development effort of short-scale programs, Neural Computing and Applications, Vol. 20, pp. 389-401, 2011.

104.S. Cerón-Figueroa, C. López-Martín, and C. Yáñez-Márquez. Stochastic gradient boosting for predicting the maintenance effort of software-intensive systems, IET Software, Vol. 14, pp. 82-87, 2020.
105.D. González-Patiño, Y. Villuendas-Rey, A. J. Argüelles-Cruz, O. Camacho-Nieto, and C. Yáñez-Márquez. AISAC: An Artificial Immune System for Associative Classification Applied to Breast Cancer Detection, Applied Sciences, Vol. 10, 515, pp. 1-22, 2020.

106.B. López-Carrera, B., and C. Yáñez-Márquez. A simple model for the entropy of a system with interacting particles, IEEE Access, Vol. 7, pp. 108969-108979, 2019.

107.A. Chavoya, I. R. Andalon-Garcia, C. Lopez-Martin, and M. E. Meda-Campaña. Use of evolved artificial regulatory networks to simulate 3D cell differentiation, Biosystems, Vol. 102, pp. 41-48, 2010.

108.E. Ventura-Molina, A. Alarcón-Paredes, M. Aldape-Pérez, C. Yáñez-Márquez, and G. Adolfo-Alonso. Gene selection for enhanced classification on microarray data using a weighted k-NN based algorithm, Intelligent Data Analysis, Vol. 23, pp. 241-253, 2019.

109.J. C. Ramirez Velez, C. Yáñez-Márquez, and J. P. Córdova Barbosa. Using machine learning algorithms to measure stellar magnetic fields, Astronomy \& Astrophysics, Vol. 619, A22, pp. 1-13, 2018.

110.I. López-Yáñez, O. Camacho-Nieto, C. Yáñez-Márquez, and A. V. Uriarte-Arcia. Fast route convergence in dynamic power controlled routing for wireless ad-hoc networks, IEEE Latin America Transactions, Vol. 11, pp. 607-608, 2013.

111.R. Sepúlveda-Lima, C. Yáñez-Márquez, I. López-Yáñez, and O. Camacho-Nieto. A Novel Solution to the Secure Exchange of Environmental Engineering Education Data, International Journal of Engineering Education, Vol. 28, pp. 1380-1387, 2012.

112.M. Aldape-Pérez, C. Yáñez-Márquez, O. Camacho-Nieto, and A. J. Argüelles-Cruz. A New Tool for Engineering Education: Hepatitis Diagnosis using Associative Memories, International Journal of Engineering Education, Vol. 28, pp. 1399-1405, 2012.

113.N. Nawaz. Artificial Intelligence Face Recognition for Applicant Tracking System. International Journal of Emerging Trends in Engineering Research, Vol. 7, no. 12, 2019.

114.N.-Kt Nguyen. A novel improving technology to intelligent controllers - a typical case study for turbine speed regulation of a smart hydropower plant. International Journal of Emerging Trends in Engineering Research, Vol. 8, No. 6, pp. 2388 - 2394, 2020.

115.O. Dahiya, K. Solanki, S. Dalal, and A. Dhankhar. An Exploratory Retrospective Assessment on the Usage of Bio- inspired Computing Algorithms for Optimization. International Journal of Emerging Trends in Engineering Research, Vol. 8, No. 2, pp. 414-434, 2020.

116.M. S. Kumar, S. Inthiyaz, M.Aditya, P. Rupanjani, B. Aravind, M. Mukesh, S. K.. Tulasi. Implementation of 
GDI Logic for Power Efficient SRAM Cell with Dynamic Threshold Voltage Levels, International Journal of Emerging Trends in Engineering Research, Vol. 7, No. 12, pp.902-906, 2019.

117.H. Khudov, S. Yarosh, V. Savran, A. Zvonko, A. Shcherba, P. Arkushenko. The technique of research on the development of radar methods of small air objects detection, International Journal of Emerging Trends in Engineering Research, Vol. 8, no.7, pp. 3708-3715, 2020. 